\title{
Arranjos produtivos
}

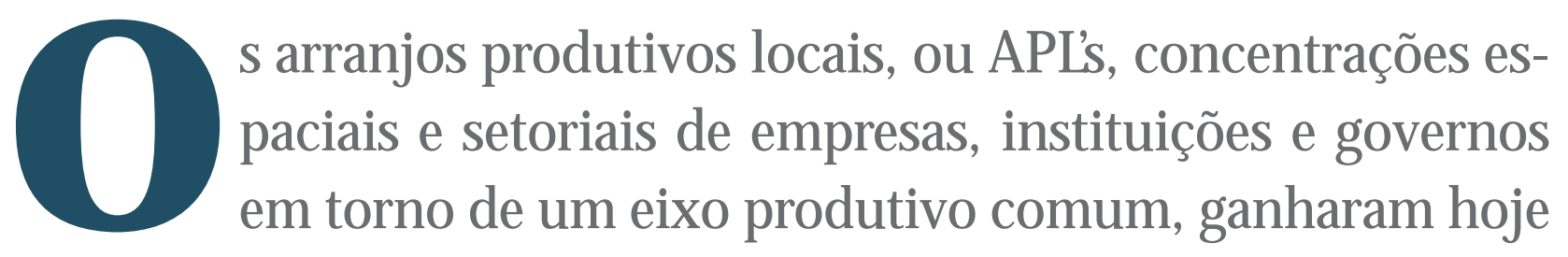
posição de destaque na pauta de debate de empresários e governantes brasileiros. Acompanha o ressurgimento desse interesse uma esperança de que tais arranjos possam contribuir para a competitividade e o desenvolvimento do país.

por Flávio C. de Vasconcelos, Rafael G. B. Goldszmidt e Fernando C. M. Ferreira FGV-EAESP

Já no final do século XIX, o economista Alfred Marshall havia observado que grupos de pequenas empresas aglomeradas da Grã-Bretanha vinham desfrutando de um significativo conjunto de vantagens quando comparadas às empresas não pertencentes às aglomerações. Em particular, elas tinham maior facilidade de acesso a recursos, à mão-de-obra especializada, a fornecedores e a outras indústrias de suporte, assim como melhor capacidade de inovação e apropriação de conhecimentos. 0 economista deu a esses aglomerados o nome de distritos industriais.

Após a segunda grande guerra, a economia mundial rapidamente se reorganizou. Isso se fez em torno de gran- 
des corporações, organizadas vertical mente, centralizadas e voltadas à produção de bens de consumo de massa. Essa nova configuração da indústria parecia ter colocado um fim no papel desempenhado pelos distritos industriais. Contudo, um século após os primeiros estudos de $M$ arshall, em plena era da internacionalização dos mercados e da orientação global da maior parte das grandes empresas, impulsionadas pela facilidade de acesso à informação e recursos em qual quer parte do planeta, o tema reaparece com renovado vigor.

0 impulso decisivo para o reaparecimento do interesse pelas aglomerações originou-se da experiência com o fenômeno denominado de Terceira Itália. No final dos anos de 1970, setores maduros da economia italiana, tais como de sapatos, de móveis, de cerâmica e têxteis, caracterizados por pequenas e médias empresas aglomeradas em limitados espaços geográficos, passaram a demonstrar maior desempenho e inserção internacional do que as grandes empresas localizadas no Triângulo Industrial italiano formado pelo eixo Milão-Gênova-Turim.

lidade de insumos ou localização geográfica, o que se convencionou chamar de geografia natural subjacente. Antes, a opção ocorre em função de características fortemente relacionadas à proximidade da demanda, custos de transporte e economias de escala, o que se denomina de a "segunda natureza" de uma região.

A origem das aglomerações industriais encontra-se na interação entre os elementos desta segunda natureza. Conjuntamente, demanda, custos de transporte e economias de escal a agem como uma força gravitacional que se torna mais poderosa à medida que maior demanda atrai mais empresas e vice-versa. Esse processo de auto-reforço leva ao estabelecimento de uma região em particular. A partir desse momento, seja uma aglomeração ou um grande centro industrial, como São Paulo, a região eleita dificilmente perderá sua posição central. Considere-se, por exemplo, o centenário cinturão de manufatura norte-americano, localizado no nordeste dos Estados Unidos.

Contudo, a centelha que dá início ao processo de aglomeração está longe de ser deliberada. As aglomerações possuem um forte background históri-

\section{Crucial para o estabeleci mento de clusters}

\section{e APL's é a presença de uma "cola social".}

Nas décadas seguintes, o termo distrito industrial, ainda que bastante utilizado na Europa, cedeu lugar aos termos clusters e Arranjos Produtivos Locais (APLs), mais especificamente no cenário brasileiro. Recentemente, no Brasil os APLs vêm recebendo uma atenção crescente de governos e da iniciativa privada. U ma esperança singular éa eles direcionada: a deserem meios estratégicos para o fomento da competitividade e do desenvolvimento econômico do país.

0 presente artigo busca delinear uma visão geral das aglomerações industriais. Em específico, analisa suas origens, os benefícios e os riscos oriundos da localização de empresas nestas áreas.

A origem das aglomerações. 0 fato é que as empresas raramente escolhem a região mais eficiente em termos de recursos naturais para se localizar. U ma empresa não opta por uma região apenas em função da disponibi- co. Até mesmo eventos fortuitos podem ter um papel crucial. Um caso clássico é o da cidade de Dalton, Estado da Geórgia (EUA), em queum novo estilo de colcha de cama tufada, feita por uma jovem como presente de casamento, criou as raízes para a formação do maior pólo de tapeçaria dos Estados Unidos. Atualmente, as maiores indústrias de tapetes daquele país lá se localizam.

Questões de defi nição. Embora o background de uma região e os elementos relacionados à segunda natureza sejam fundamentais para o estabelecimento de aglomerações industriais, estes não são suficientes para caracterizá-las como um cluster ou um APL. O bserva-se hoje, não apenas no Brasil, um verdadeiro modismo na utilização desses dois termos. A classificação de determinadas regiões, sem evidências consistentes, como clusters ou APLs prolifera em associações e na academia. Freqüentemente, a existência da aglomeração de empresas de uma determinada indústria em uma cidade ou região já é tomada como condição suficiente para incluí-la em uma dessas classificações. 
Crucial para o estabelecimento de clusters e APLs é a presença de uma "cola social", oriunda de redes de relacionamentos entre empresas semelhantes e entre estas e seus fornecedores e provedores de serviços locais, do papel das instituições de ensino, pesquisa e associações regionais. Tal rede tem relevante impacto sobre os processos de cooperação e competição, criação e difusão de conhecimento dentro da aglomeração. Essas características são fundamentais para determinar se, de fato, uma aglomeração se enquadra em uma dessas classificações.

Princi pais benefíci os. Não são poucas as vantagens da localização em clusters earranjos produtivos locais. 0 ambiente institucional em que os membros dessas formas de aglomeração estão imersos consiste em fonte de vantagem para as empresas neles localizadas. A organização desses aglomerados e suas instituições formais (regras e leis) e informais (normas e costumes), ao fornecerem um parâmetro para 0 processo de tomada de decisões e para as relações que ocorrem entre as empresas, tem papel crucial na redução da incerteza. Assim, mesmo quando há espaço para a formalização das atividades entre as empresas, parte considerável da coordenação é realizada via redes de relacionamento.

Além da economias em custos de transação, potencializada pela proximidade entre as empresas e a facilidade e velocidade de comunicação em um limitado espaço geográfico, há inúmeros outros benefícios nãopecuniários oriundos dos APLs. Entre estes, o de maior destaque talvez seja o knowledge spillover - que se refere ao efeito da transposição do conhecimento tácito ou não codificado para além das fronteiras da empresa, atingindo suas contrapartes ao longo do aglomerado e a ele se restringindo. Esse conhecimento não se encontra em fórmulas e projetos, mas é inerente às habilidades pessoais e procedimentos operacionais que não se prestam a definições explícitas. Atribui-se a esse efeito, entre outros aspectos, a capacidade de rápida difusão de inovações ao longo do aglomerado, geralmente em função de contatos pessoais de empreendedores e colaboradores das empresas.

Os maiores benefícios derivados da localização nesses aglomerados parecem ter origem na interação entre os processos de cooperação e competição. A cooperação pode

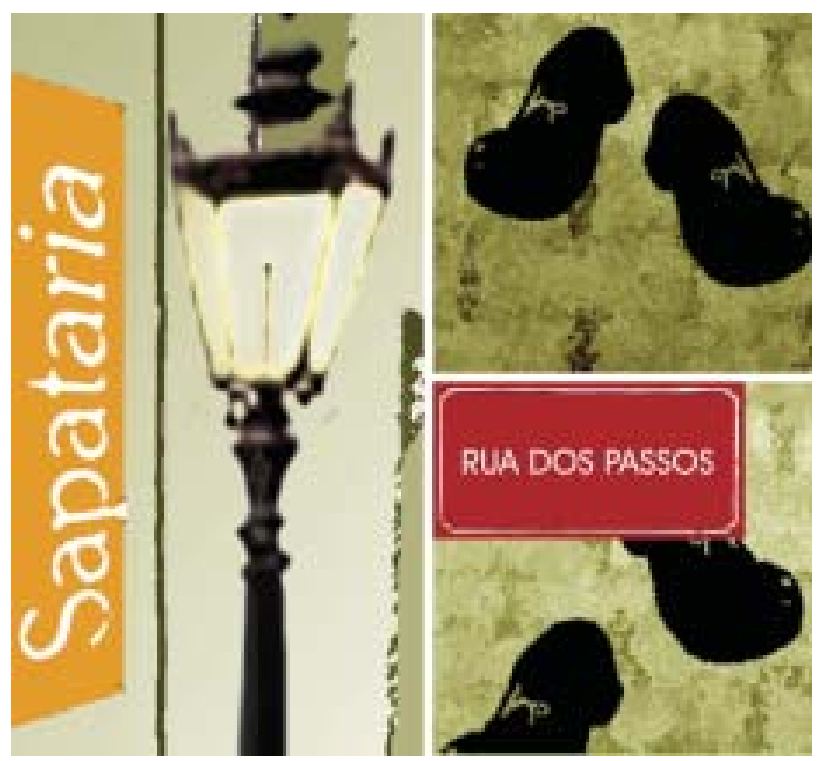

ocorrer tanto horizontalmente, ou seja, entre as empresas do aglomerado de atividade semelhante, como verticalmente, englobando toda a cadeia produtiva, organismos locais de suporte e setor público. As ações conjuntas intencionais - tais como esforços de compras ou marketing podem se traduzir em ganhos competitivos importantes para as empresas, permitindo, coletivamente, superar obstáculos que estas, isoladamente, teriam maiores dificuldades em transpor.

Contudo, a competitividade das empresas pode também ser aumentada por meio de processos de competição dentro da aglomeração, conduzindo à rápida adoção de inovações e melhorias e, dessa forma, gerando o crescimento da indústria. Além disso, a competição em um cluster ou APL tem o potencial de aumentar a produtividade das companhias neles localizadas, conduzir a direção e o ritmo de inovação e estimular a formação de novos negócios, o que provoca a expansão e o fortal ecimento do próprio aglomerado.

O outro lado da moeda. Embora se exaltem muitos dos benefícios da local ização em clusters ou APLs, pouco se diz que esses sistemas estão longe de refletir o melhor dos mundos. Em algumas circunstâncias, é até mesmo preferível a uma empresa manter-se fora de um aglomerado industrial a tornar-se parte dele. 


\section{Apoio aos APLs paulistas}

A Federação das Indústrias do Estado de São Paulo (Fiesp), em particular a Gerência de Competitividade e Tecnologia Decomtec - acumula experiência de mais de cinco anos no apoio ao desenvolvimento da competitividade de micros, pequenas e médias empresas (MPMEs) paulistas inseridas em APLs. 0 pressuposto central que norteia 0 trabalho da instituição é a idéia de promover o desenvolvimento econômico local por meio do incremento da competitividade das MPMEs locais. Para tanto, a Fiesp busca assessorar essas empresas por meio de soluções nas áreas de tecnologia e inovação, gestão, mercado, recursos humanos, empreendedorismo, capital e cooperação. A seguir, apresentamos algumas das principais características da metodologia de projetos da Fiesp.

0 projeto divide-se, metodologicamente, em dois grupos. Um grupo de empresas denominado de grupo piloto e outro formado pelas lideranças e representantes da governança local, chamado de grupo gestor. A finalidade do grupo piloto é funcionar como uma espécie de incubador e difusor de novas práticas rumo a produtividade e competitividade.

Por meio dele é possível customizar soluções para a localidade, iniciar um trabalho de mudança de comportamento na direção de ações coletivas e, por meio de um efeito de demonstração, gerar um movimento de transbordamento (spillover) de melhores práticas de gestão empresarial baseadas em um novo modelo mental. Esse grupo permite analisar os resultados das implementações efetuadas por meio de constantes avaliações de indicadores de performance e de clima motivacional para a mudança, permitindo correções de rumo, eficiência e eficácia das soluções implementadas.

No que diz respeito aos grupos gestores, estes são formados pelo poder público dos locais em que se situam as aglomerações, por representantes da sociedade civil e dos setores econômicos envolvidos. 0 objetivo deste grupo é articular, integrar e coordenar os esforços dos agentes locais e/ou da região e dos recursos disponíveis, formando um grupo permanente de discussões sobre interesses comuns do pólo, mantendo e vigiando o comprometimento com relação ao projeto.

Atualmente, o projeto da Fiesp atende a 154 empresas diretamente e a outras 797 de forma indireta distribuídas por todo 0 estado de São Paulo. Com base na experiência e no contato com a realidade desses diversos aglomerados, a instituição destaca alguns pontos críticos para seu desenvolvimento, que sumarizamos a seguir.

- É preciso estimular mudanças. Para o crescimento dos APLs, é necessário o desenvolvimento de novas competências por meio de processos contínuos de mudança. Pesquisa de mercado; consultoria para desenvolvimento e implantação de projetos, com acompanhamento contínuo; seminários de formação gerencial; treinamentos técnicos; e assessoria para mudança de comportamentos e cultura são alguns dos exemplos de ferramentas que podem ser empregadas para essa finalidade.

- É preciso sistematizar informações. A experiência da Fiesp mostra que, à medida que as informações críticas forem sistematizadas e transformadas em subsídios para a realização do planejamento estratégico das MPMEs, inseridas ou não em APLs, iniciase um movimento de conscientização dos empresários, levandoos a romper a mera estratégia de sobrevivência e a vislumbrar novos planos de crescimento e desenvolvimento estratégicos.
- É preciso desenvolver expertise local. Outro ponto importante a destacar é que qualquer mudança deve ser feita pelos próprios protagonistas locais; do contrário, corre-se 0 risco de verem se repetir políticas passadas de caráter impositivo ou então sem conhecimento de causa sobre a realidade vivida por cada localidade. Daí a importância de desenvolver uma coordenação entre os agentes locais, tanto públicos quanto privados.

- É necessário promover um ambiente de confiança entre os agentes envolvidos. 0 processo de desenvolvimento do ambiente de confiança deve ser feito entre todas as partes. Começa com a auto-confiança dos empresários, passa pela confiança entre os empresários, a confiança dos empresários nas instituições envolvidas e, por fim, na confiança entre as instituições que atuam localmente. 
Sob certas circunstâncias, a participação em clusters ou APLs pode retardar a inovação. 0 desenvolvimento de um pensamento grupal nas empresas pertencentes a tais tipos de aglomeração pode implicar o reforço de comportamentos antigos, enquanto novas idéias são suprimidas e cria-se rigidez que impede a adoção de melhorias. Mudanças no mercado podem tornar os ativos, tais como as habilidades dos funcionários, o know-how e as bases de fornecedores, obsoletos. Devido a essa rigidez, essas aglomerações podem não suportar 0 advento de inovações radicais e, conseqüentemente, entrar em decadência.

Boa parte dos processos de cooperação parte do pressuposto de que as empresas possuem posições semeIhantes e de que 0 acesso a recursos locais também é semelhante. Em outras palavras, há pouca disparidade de poder entre as empresas do aglomerado. Ironicamente, porém, o desenvolvimento de um cluster ou APL pode significar o distanciamento daquilo a que ele se propõe: aumento da competitividade baseado em uma relação de poderes equânime. 0 surgimento das grandes corporações durante a evolução desses tipos de aglomerações dá início ao desequilíbrio nas relações de poder e mina as bases fundamentais das redes de relacionamento. A confiança se restringe, as relações se formalizam e os benefícios delas oriundos se dissipam.

Entretanto, se 0 incentivo à competição nos clusters ou APLs pode ser um importante fomento à inovação, 0 equilíbrio entre os processos de cooperação e competição não é sempre positivo. Apesar da possível existência de processos de cooperação entre as empresas, as organizações aglomeradas poderiam encontrar-se imersas em um processo de competição tão acirrado que os efeitos negativos deste acabariam anulando os benefícios gerados pela cooperação. Tal competição exacerbada poderia ser oriunda de uma excessiva similaridade entre as estratégias adotadas pelas diferentes empresas, com limitada diferenciação dos produtos e semelhanças em termos de abordagens mercadológicas e público atendido, o que poderia levá-las a um prejudicial processo de competição baseada no preço.
Cautela e apoi o. 0 cenário brasileiro apresenta um amplo conjunto de aglomerações industriais dos mais variados setores. Porém, a percepção de que há uma hiperestimação dos arranjos produtivos locais e clusters no país se torna cada vez mais crescente. Seria conveniente abandonar a incansável tendência de avaliar se uma aglomeração merece uma das possíveis classificações e procurar compreender sua dinâmica, seus processos de formação e as possibilidades de ações das iniciativas privada e governamental. ajuda a minimi zar as desvantagens advindas do pequeno porte, confere às pequenas empresas a flexibilidade e o dinamismo freqüentemente ausentes nas grandes. merações industriais em clusters ou APLs é um processo de longo prazo. Não se constroem redes de relacionamentos do dia para a noite e tampouco se estabelecem essas formas deaglomeração intencional mente, apenas com base em uma iniciativa privada ou governamental. 0 que a história nos tem dito é que, na maioria das vezes, a melhor política em relação aos clusters não étentar criá-los, mas oferecer apoio, seja ele político, econômico ou institucional, para conduzir as aglomerações a novos patamares competitivos.

Flávio Carvalho de Vasconcelos

Prof. do Departamento de Administração Geral e Recursos Humanos da FGV-EAESP

Doutor em Administração pela Ecole des Hautes Études Commerciales

E-mail: fvasconcelos@fgvsp.br

Rafael G. Burstein Goldszmidt

M estrando em Administração de Empresas na FGV-EAESP

E-mail: rafaelgoldszmidt@gvmail.br

Fernando Coelho Martins Ferreira

Doutorando em Administração de Empresas na FGV-EAESP

E-mail: fferreira@gvmail.br 